\title{
AN ANALYSIS ON THE INTRAINDIVIDUAL DIFFERENCE IN L1 AND L2 UTTERANCES IN THE SAME CONTEXT
}

\author{
Noriko Aotani ${ }^{1}$, \& Shin'ya Takahashi ${ }^{2}$ \\ ${ }^{1}$ School of Education \\ ${ }^{2}$ School of Psychology \\ Tokai Gakuen University (Japan)
}

\begin{abstract}
A longstanding problem that English education in Japan has been struggling with is that learners cannot develop communication skills in English. Learners have rarely been trained to express their internal concerns subjectively, that is how they think or feel about external things, in English. This study investigated, using twelve university students, how and what they say in English and in Japanese when confronted with a thought-provoking situation. By comparing the data, our hypothesis that they would describe the situation more objectively in English than in Japanese was confirmed. The results were discussed in the context of the problems of current English programs and some pedagogical suggestions were made.
\end{abstract}

Keywords: Intraindividual difference, Japanese ESL learners, objective description, subjective expression.

\section{Introduction}

Japanese people are often said to be timid in English conversation despite the fact they have been extensively taught English in schools. One of the possible reasons for this problem may be the content of English-learning in these classes that tend to focus on how to describe external things or events objectively (e.g., 'A rainbow is caused by the refraction of light inside raindrops.'). They have been rarely trained to express their internal concerns subjectively, that is how they think or feel about external things, in English (e.g., 'How beautiful that rainbow is!'). Consequently, they have developed an objective attitude in using English, trying to describe what they encounter as correctly and fluently as possible, while hesitating to express their feelings and emotions that have no objective truth. In the present study, as the first step to confirm the above conjecture and thereby contribute to the improvement of the English-learning program in Japan, we explored how and what Japanese young people say in English and in Japanese when confronted with a thought-provoking situation. Our hypothesis is that they would describe the situation more objectively in English than in Japanese.

\section{Methods}

\subsection{Participants}

Twelve university students ( 9 males and 3 females, mean age 20.9 years old), all majoring in English education, participated in the experiment.

\subsection{Materials}

Fourteen pictures, collected from copyright-free materials on the Internet, were used as stimuli (see Figure 1). They were seven pairs of the same subjects, skydiving, cake, lion, party, mountain, couple, and monkey. Two sets of these seven pictures were used in the first and the second halves of the experiment. Pictures were projected on a whiteboard ( 29 x 39 degree).

\subsection{Procedure}

Participants watched pictures one by one for one minute each and were instructed to say anything that came to their mind. He or she talked to himself or herself, not having a conversation with the experimenter. 
In the first and the second halves, the language to be used was changed from Japanese to English, or vice versa. The order of languages was counterbalanced among participants.

Figure 1. Samples of the pictures used in the experiment (from left, cake, party, and monkey).
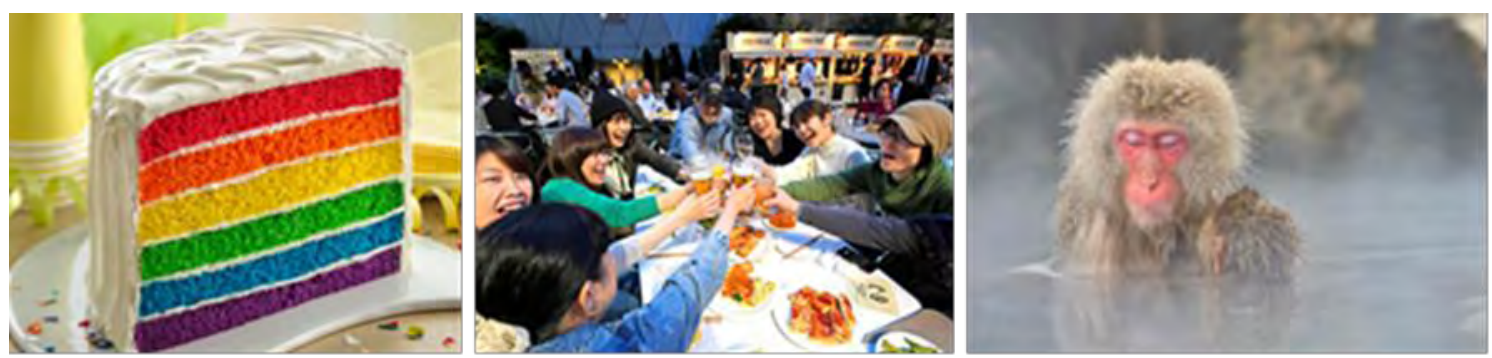

\subsection{Data Processing}

Participants' utterances were recorded and transcribed. Then, they were segmented into meaning units, and each meaning unit was classified as either objective description of what is shown on the picture (e.g., 'they drink alcohol') or subjective expression of what participant imagined (e.g., '(they are) maybe company colleagues'), what he or she was impressed (e.g., 'what a beautiful cake'), and a feeling of his or her own (e.g., 'I want to go to hot springs').

\section{Results}

Figure 2 shows the number of meaning units classified as objective description or subjective expression in Japanese and English utterances in each participant. As shown here, the ratio of subjective expression was higher in Japanese than in English for all participants. In ten of twelve participants, such a difference was supported with statistical significance by the chi-square test.

Next, we picked out self-related items from the subjective expression units, such as 'I want to do it once in my life,' 'I've seen it before,' and 'I don't like sweets'. For all data it the total was 145 ( $M$ 12.1, SD 11.5) in Japanese and 72 ( $M$ 6.0, SD 9.9) in English. This difference was revealed to be significant $\left(F=21.15, d f=1,11, p=.001, \eta^{2}=.658\right)$.

Figure 2. Number of meaning units classified as objective description or subjective expression in Japanese and English utterances for each participant $(A-L)$. The area of background indicates its ratio in each language. The result of chi-square test is shown below each panel, significant case indicating different ratio between languages.

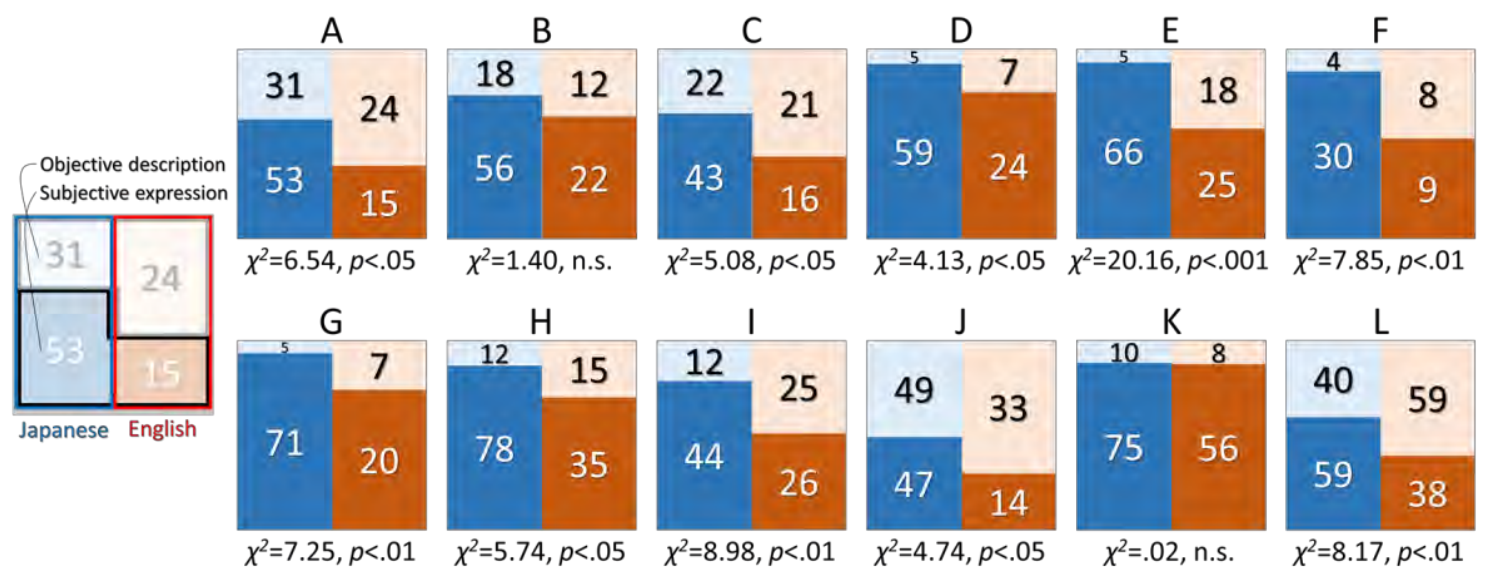

\section{Discussion}

Many Japanese people are not content with their English proficiency, especially in speaking, despite receiving six years of English education (recently it has become even longer). They learn from 3,000 to 5,000 words and sufficient grammar for describing what they see and how they feel about that. Although lack of opportunity to communicate with others in English either in classrooms or daily life prevent them from acquiring fluency, they must have ability to express things in English if they are given enough time for semantic processing. Those who have not achieved fluency tend not to think in English, but to try to translate what they think in Japanese into English. If this is their process, their utterances in 
Japanese and English should be alike. This study, however, revealed the quality of what they utter in English is different from that in Japanese. They tended to make more subjective utterances in Japanese than in English. As shown in Figure 2, half of the participants (A, C, F, I, J, and L) made subjective expressions in about $50 \%$ or less of all English utterances, whereas most of them made overwhelmingly more subjective units than objective units in Japanese. In addition, detailed analysis of the data showed that Japanese are less inclined to express self-related things in English than in Japanese. Our hypothesis that Japanese would describe the situation more objectively in English than in Japanese was (unfortunately) supported by the present data. According to a short interview conducted with each participant after the experiment for their feedback, some participants can focus on the main theme of the picture, i.e. cake, beer party, monkey etc., and express their feelings about it in the case of Japanese. On the other hand, however, their direction of eyes spread throughout the picture in the case of English, and as a result, their utterances tended to become the objective description of anything seen on the picture. This implies the fact that English has not become a language to express their emotions.

In order to investigate the causes of this result, we have to consider it in the context of English education in Japan. One of the problems to be pointed out is an authenticity of learning materials used in junior high and high schools. Since texts are usually chosen from the viewpoint of educational appropriateness rather than authenticity, even texts used in the conversation parts are far from colloquial common expressions (Kobayashi, 2013), which is indispensable for expressing one's feeling in natural conversations. In the case of vocabulary acquisition, after a new word is introduced with its Japanese translation, acquiring the usage of the word in real life is left up to learners. Although many words are polysemous, the chances of expanding vocabulary knowledge are limited. Learners think they know the word; however, they do not even notice that there are other meanings (Aotani, 2010, 2012), therefore, in production, the ranges they can express are then very narrow. Japanese and English are regarded as distant languages. The more they perceive formative differences, the longer the psychological distance they feel between the two languages seems to become (Kellerman, 1977). In such a situation, they tend to be reluctant to utilize their L1 knowledge and believe straightforward translation from Japanese to English does not work very well in order to produce 'good English'. English education in Japan has been focusing on accuracy rather than fluency. Learners have always been under pressure to produce grammatically correct sentences. Considering this educational background, in this study, we instructed participants not to worry about grammatical accuracy. We did not require sentence-level utterances, allowing word-by-word utterances. Despite this encouragement, their quantity of utterances in English was still far less than that in Japanese. Some participants mentioned in the interview that it was due to their mentality. Matsuoka (2008) investigated college students' communication apprehension, and pointed out personality traits such as perfectionism, competitiveness, 'good-student' mentality and face-protecting orientation may generate communication apprehension. Going back to the individual data of this study, participant K (male, 22 years old) stood out from others. K's English proficiency level is not particularly higher than other participants, but he is a highly motivated learner of English since he is going to work abroad from this coming spring. His case implies having high motivation, which is definitely one of the most desired factors for language learning, can overcome learners' apprehension.

The new National Curriculum Standards in Japan were enforced in 2017, and the beginning age of studying English in public schools was accelerated from 5th graders to 3rd graders. The priority of the revision is to revise the curriculum to be suitable for a rapid progress of globalization and to make English education focus more on enhancing learners' communication skills than ever before. In real-life communication, expressing one's feeling is a fundamental factor for mutual understanding, and how to enhance this ability should be one of the priorities in English education in Japan.

\section{References}

Aotani, N. (2010). An Analysis on How Japanese Learners of English Perceive Polysemous Senses of Words That Are Peculiar to English - Based on the acceptability patterns of the senses of 'run'. Proceedings of the 15th Conference of Pan-Pacific Association of Applied Linguistics, 267-272.

Aotani, N. (2012). Profiles of Japanese EFL learners and their acceptance of transfer in word meaning expansion. Proceedings of the 5th CLS International Conference, 14-22.

Kellerman, E. (1977). Towards a Characterization of the Strategy of Transfer in Second Language Learning. Interlanguage Studies Bulletin, 2/1, 53-145.

Kobayashi, T. (2013). Testing the authenticity of the Colloquial Expressions in New Junior and Senior High School English Textbooks Approved by the Ministry of Education and the Five Urgency Proposals. Otaru University of Commerce, The Review of Liberal Arts, 126, 155-200.

Matsuoka, R. (2008). Communication Apprehension among Japanese College Students. Journal of Pan-Pacific Association of Applied Linguistics, 12(2), 37-48. 